\title{
Facilitating Effects of Fast and Slope Walking on Paraspinal Muscles
}

\author{
Hee Song Lee, $\mathrm{MD}^{1}$, Jae Sun Shim, $\mathrm{MD}^{1}$, Seok Tae Lee, $\mathrm{MD}^{1}$, \\ MinYoung Kim, MD, $\mathrm{PhD}^{1}$, Ju Seok Ryu, $\mathrm{MD}, \mathrm{PhD}^{2}$ \\ ${ }^{1}$ Department of Rehabilitation Medicine, CHA Bundang Medical Center, CHA University, Seongnam; \\ ${ }^{2}$ Department of Rehabilitation Medicine, Seoul National University Bundang Hospital, \\ Seoul National University College of Medicine, Seongnam, Korea
}

Objective To quantify the activation of the paraspinalis muscles (multifidus and erector spinae) at different walking velocities and slope with surface electromyography.

Methods This study was a prospective experimental study involving ten healthy male participants. Surface electrodes were placed over the multifidus and erector spinae muscles at the L5 and L3 level. After the electrode was placed at the lumbar paraspinalis muscles, electromyography signals were recorded over 20 seconds. Data were collected three times during the walking exercise at a $0^{\circ}$ gradient with the speed from 3 to $6 \mathrm{~km} / \mathrm{hr}$. At $7^{\circ}$ gradient and $15^{\circ}$ gradient, data were also collected three times but a walking speed of $4 \mathrm{~km} / \mathrm{hr}$. The area under the curve was calculated for quantitative measurement of muscle activation.

Results While the muscle activation was increased at higher walking velocities at the L5 and L3 levels of the multifidus, the erector spinae muscle activation did not show any change at higher walking velocities. At L3 level of the multifidus and erector spine muscles, the muscle activation was significantly increased in $15^{\circ}$ gradient compared to those seen in at $0^{\circ}$ gradient. At L5 level, the multifidus and erector spinae muscle activation in $0^{\circ}$ gradient was not significantly different from that those seen in $7^{\circ}$ or $15^{\circ}$ gradient.

Conclusion Fast walking exercise activates lumbar multifidus muscles more than the slow walking exercise. Also, the mid lumbar muscles are comparatively more activated than low lumbar muscles when the walking slope increases.

Keywords Walking, Paraspinal muscles, Low back pain

Received April 3, 2014; Accepted June 30, 2014

Corresponding author: Ju Seok Ryu

Department of Rehabilitation Medicine, Seoul National University Bundang Hospital, Seoul National University College of Medicine, 82 Gumi-ro 173 beon-gil, Bundang-gu, Seongnam 463-707, Korea Tel: +82-31-787-7731, Fax: +82-31-712-3913, E-mail: jseok337@hanmail. net

@ This is an open-access article distributed under the terms of the Creative Commons Attribution Non-Commercial License (http://creativecommons. org/licenses/by-nc/3.0) which permits unrestricted noncommercial use, distribution, and reproduction in any medium, provided the original work is properly cited.

Copyright $\odot 2014$ by Korean Academy of Rehabilitation Medicine

\section{INTRODUCTION}

Low back pain (LBP) is an extremely common disorder with reports of lifetime prevalence as high as $80 \%$ [1]. In some patients, the initial acute pain continues over six months and eventually develops into a chronic LBP [2]. Most patients with chronic LBP complain of continuous pain and do not respond to medication or physical therapy. LBP can eventually lead to muscle weakness in the lower back due to a lack of exercise [3]. In a study by 
Lee et al. [4], the initial cross-sectional area of the erector spinae muscles at L5 in patients with no improvement in their back pain were significantly smaller six months after the trauma than those with improved back pain. Therefore, the size of the lumbar muscle area and the degree of muscular atrophy have relationship with relapse into back pain.

The lumbar multifidus muscle plays an important role in maintaining lumbar segmental stability as it connects each segments of the lumbar spine. In healthy adults the lumbar multifidus muscle is equally distributed on both sides of the lumbar area $[5,6]$, with a larger crosssectional area in the lower parts of the lumbar spine [5]. Contrary to adults with healthy distribution, patients with chronic LBP were found to have severe atrophy of the lumbar multifidus muscle in the lower parts of the lumbar spine [7].

For patients with chronic LBP, exercise therapy that specifically activates the multifidus of the segmental level reduces pain and recurrence of LBP $[8,9]$. Multifidusfacilitating exercise is an established part of the active treatment modalities of chronic LBP in rehabilitation [10]. Therefore, a variety of exercises can be performed to facilitate the trunk muscles, especially the multifidus and erector spinae muscles. However, no specific exercise has been proved to be superior over others. Further research is necessary to determine which exercise is the most effective.

Electromyography (EMG) can be used not only for diagnosing neuromuscular disease but also for selecting back muscles that can be analyzed during exercise [11]. Surface EMG (SEMG) analysis can be used to further observe changes in lower back muscles during rehabilitation exercises [11]. Using SEMG in chronic LBP patients, a study by Ekstrom et al. [12] found differences in the activity of the multifidus and the erector spinae muscles that depended on the types of exercise the patients performed.

Walking is easily applicable to LBP rehabilitation and has high compliance. Walking may lead to isometric endurance by increasing muscular endurance and eventually lead to prevention of LBP [13]. In previous studies using SEMG, the amplitude of SEMG recording trunk muscles increased as the speed of the locomotor increased [14,15]. Lamoth et al. $[16,17]$ demonstrated that patients with chronic LBP had difficulty adjusting their lumbar erector spinae (LES) activity to changes in walking velocity. They used the SEMG to assess LES activity during treadmill walking at six different velocities. How- ever, they did not consider the area of SEMG, but mean amplitude of SEMG.

Until now, no study has assessed which lumbar muscle is more affected by different walking velocities using under area curves that reflect integral trunk muscle activation. Calculating the area under the curve of SEMG seems to be the most plausible method of measuring LES activity because walking is an isotonic exercise. Furthermore, no study has used SEMG to evaluate the effects of walking at different inclinations on lumbar paraspinalis muscles. This study uses the area under the curves of SEMG to assess the facilitating effects of fast and slope walking on paraspinal muscles at low and mid lumbar levels.

The primary objective of this study was to quantify the activation of the paraspinalis muscles (multifidus and erector spinae) at different walking velocities using SEMG and to ascertain the most effective walking speed for exercising the lumbar paraspinalis muscles. The second objective was to evaluate the differences in the activation of paraspinalis muscles between mid and low lumbar levels. The third objective was to evaluate the effect of inclination on the activation of the paraspinalis muscles during walking exercise. The results of this study will help elucidate the effects of walking using different muscles and help find the most effective walking speed and degree of inclination for treating patients with LBP.

\section{MATERIALS AND METHODS}

\section{Subjects}

A cross-sectional study was conducted from December 2012 to March 2013. Ten healthy males (average age $30.0 \pm 2.7$ years; height $174.0 \pm 4.9 \mathrm{~cm}$; weight $73.6 \pm 7.8 \mathrm{~kg}$; body mass index $24.3 \pm 2.1 \mathrm{~kg} / \mathrm{m}^{2}$ ) participated. Individuals were accepted into the study if they were in good health and had no current back or lower extremity problems. Those with previous or current respiratory, cardiovascular, neurological, or psychological conditions; LBP; or musculoskeletal disorders affecting the spine or limbs were excluded. The study protocol was approved by the Institutional Review Board of the CHA Bundang Medical Center, and all participants provided written informed consent.

\section{Methods}

Walking at different velocities

Walking speed was controlled by a treadmill. Prior to 
electrode placement, the participants were familiarized with the procedures. Participants were instructed to step onto the center of the treadmill belt and stand in a comfortable posture. They then walked at a constant speed on the treadmill, with comfortable arm swing. The walking speed was set to $3,4,5$, and $6 \mathrm{~km} / \mathrm{hr}$.

An electrode was then placed on the lumbar paraspinalis muscles, and the participants walked for 10 seconds before SEMG signals were recorded. The recordings were repeated three times at each speed $(3,4,5$, and $6 \mathrm{~km} / \mathrm{hr})$. Rest periods of 30 seconds were allowed between repetitions of each step, and a 1-minute rest period was given between the different velocities to help reduce the effects of fatigue.

\section{Walking at different inclinations}

Participants walked at a $0^{\circ}, 7^{\circ}$, and $15^{\circ}$ inclination with a walking speed of $4 \mathrm{~km} / \mathrm{hr}$. They walked for 10 seconds before EMG signals were recorded. The recordings were repeated three times at each inclination $\left(0^{\circ}, 7^{\circ}\right.$, and $\left.15^{\circ}\right)$. Rest periods of 30 seconds were allowed between repetitions of each step a 1-minute rest period was given between the different inclinations to avoid the fatigue influencing the results.

\section{SEMG recording}

Unilateral SEMG of four lumbar muscles were recorded: multifidus and erector spinae muscles at the L5 and L3 levels. Electrodes were placed $2 \mathrm{~cm}$ lateral to the spinous process for multifidus muscles, and the electrodes were placed $4 \mathrm{~cm}$ lateral to the spinous process for the erector spinae muscle [12,18-20] (Fig. 1).

The sites of electrode placement were prepared by abrading the skin with fine sandpaper and cleansing the area using $70 \%$ isopropyl alcohol. Excess hair was shaved off when necessary. The SEMG of each muscle was recorded using small disposable electrodes $(\mathrm{Ag} / \mathrm{AgCl}$ discs, 10-mm diameter; CareFusion, San Diego, CA, USA) in a bipolar configuration. A reference electrode $(\mathrm{Ag} / \mathrm{AgCl}$ discs, 10-mm diameter; CareFusion) was placed at the tip of the spinous process or on the posterior superior iliac spine. Paper tape was applied over the electrodes to minimize any movement of the electrodes during the walking.

After the participants walked for 10 seconds, the examiner started recording the SEMG signals and it was
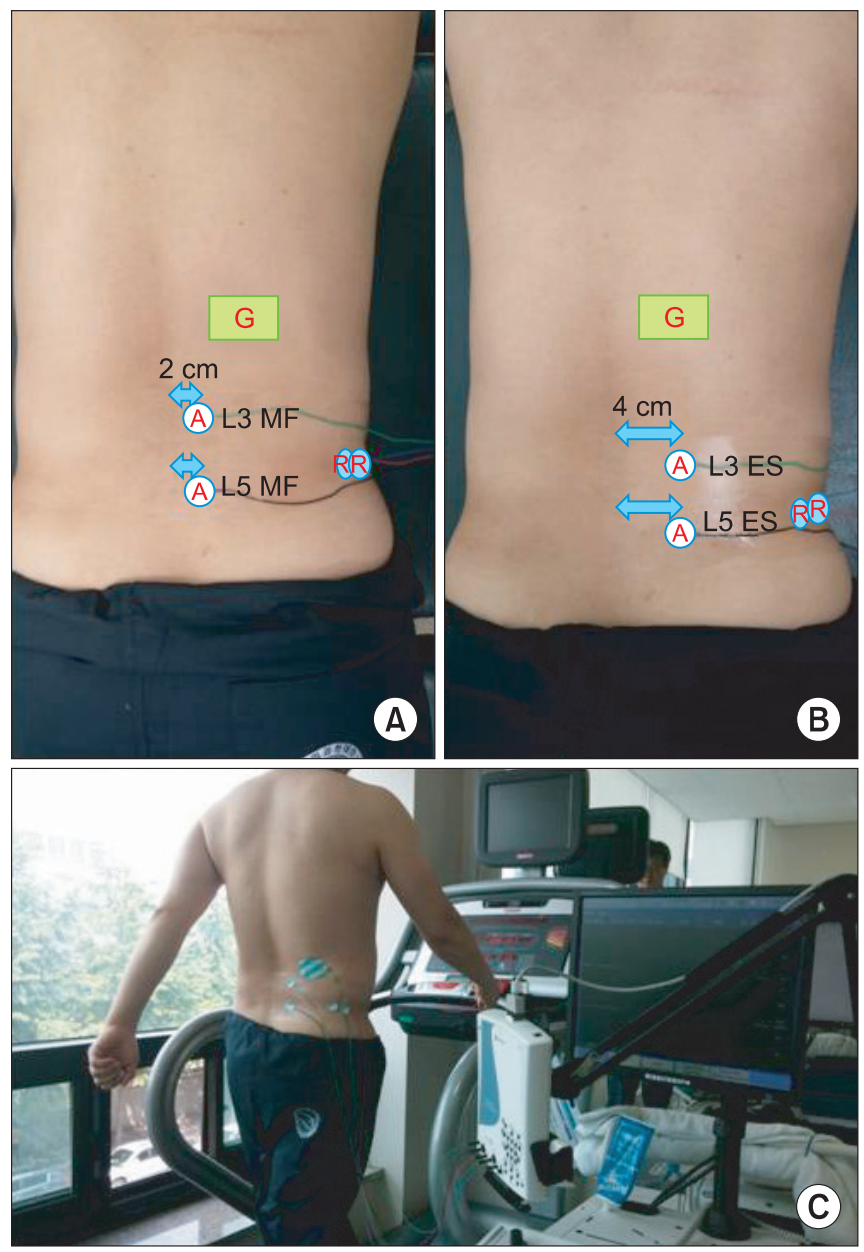

Fig. 1. (A) Active electrodes are attached $2 \mathrm{~cm}$ away (lateral) from the spinous process to record the multifidus (MF) activity and the reference points are located at the iliac bone. (B) Active electrodes are attached $4 \mathrm{~cm}$ away (lateral) from the spinous process to record the erector spinae (ES) activity and the reference points are located at the iliac bone. (C) Surface electromyography recording of a participant on a treadmill to record erector spinae muscle activity at L3 and L5 level.

stopped automatically after 20 seconds. The initial 10 seconds delay was given to obtain the representative muscle activation during the treadmill test, as patients tend to show abnormal muscle activation during the initial habituation process.

\section{Data analysis}

The SEMG signals were acquired using an eight-channel EMG Nicolet EDX (Natus Medical Inc., San Carlos, CA, USA). The SEMG signals were bandpass filtered from 20 to $250 \mathrm{~Hz}$. Full-wave rectification was used. Because 
the area under curve was measured, smoothing was not used.

EMG signals were digitized at a sampling frequency of $1,200 \mathrm{~Hz}$, EMG data were stored on a personal computer, and Viking electrodiagnostic software (ver. 20.0.34; Natus Medical Inc.) was used for data processing and analysis. The raw EMG was stored in the computer for digital processing, and Viking electrodiagnostic software was used for data processing and analysis. During data collection, the raw EMG recordings were monitored. The area under curve $(\mathrm{mV} \cdot \mathrm{ms})$ was calculated for quantitative measurement of muscle activation.

\section{Statistical analysis}

The Wilcoxon signed-rank test was used to determine the main effects of walking speed ( 3 vs. $4 \mathrm{~km} / \mathrm{hr}, 3 \mathrm{vs.} 5$ $\mathrm{km} / \mathrm{hr}$, and $3 \mathrm{vs.} 6 \mathrm{~km} / \mathrm{hr}$ ) on the area under curve of the EMG signal. Significant differences ( $p$-values) were analyzed using Bonferroni correction. The Wilcoxon signedrank test was used to determine the effects of inclination $\left(0^{\circ}, 7^{\circ}, 15^{\circ}\right)$; Bonferroni correction was also used.

Univariate regression analysis was used to determine the linearity of the relationship between the amount of muscle activation and walking speed. The results are reported as the mean \pm standard deviation in the text, and as the mean and standard error of the mean in the figures. The level of statistical significance employed was $\mathrm{p}<0.05$.

\section{RESULTS}

The effect of velocity

At the L5 and L3 levels of the multifidus, muscle ac- tivation was increased at higher walking velocities. At the L5 level, the area under curve was increased from $2,869.6 \pm 811.5 \mathrm{mV} \cdot \mathrm{ms}$ at $3 \mathrm{~km} / \mathrm{hr}$ to $3,669.6 \pm 1,240.9$ $\mathrm{mV} \cdot \mathrm{ms}$ at $5 \mathrm{~km} / \mathrm{hr}$ and $4,745.4 \pm 2,343.8 \mathrm{mV} \cdot \mathrm{ms}$ at $6 \mathrm{~km} / \mathrm{hr}$. At the L3 level, the area under curve was increased from $2,712.0 \pm 517.7 \mathrm{mV} \cdot \mathrm{ms}$ at $3 \mathrm{~km} / \mathrm{hr}$ to $3,616.2 \pm 925.9 \mathrm{mV} \cdot \mathrm{ms}$ at $5 \mathrm{~km} / \mathrm{hr}$ and $4,341.4 \pm 1,522.6 \mathrm{mV} \cdot \mathrm{ms}$ at $6 \mathrm{~km} / \mathrm{hr}$. Compared to muscle activation in $3 \mathrm{~km} / \mathrm{hr}$, multifidus muscle activation was significantly greater at $5 \mathrm{~km} / \mathrm{hr}$ and $6 \mathrm{~km} /$ $\mathrm{hr}$ (both $\mathrm{p}<0.05$ ) (Table 1). When the linearity of the curve at the L5 and L3 levels of the multifidus muscle was assessed by univariate regression analysis, the linearity was not proportionally increased at $4 \mathrm{~km} / \mathrm{hr}(\mathrm{p}>0.05)$. However, the linearity was proportionally increased at $5 \mathrm{~km} /$ $\mathrm{h}$ and $6 \mathrm{~km} / \mathrm{hr}$ (both $\mathrm{p}<0.05$ ). The increase in multifidus

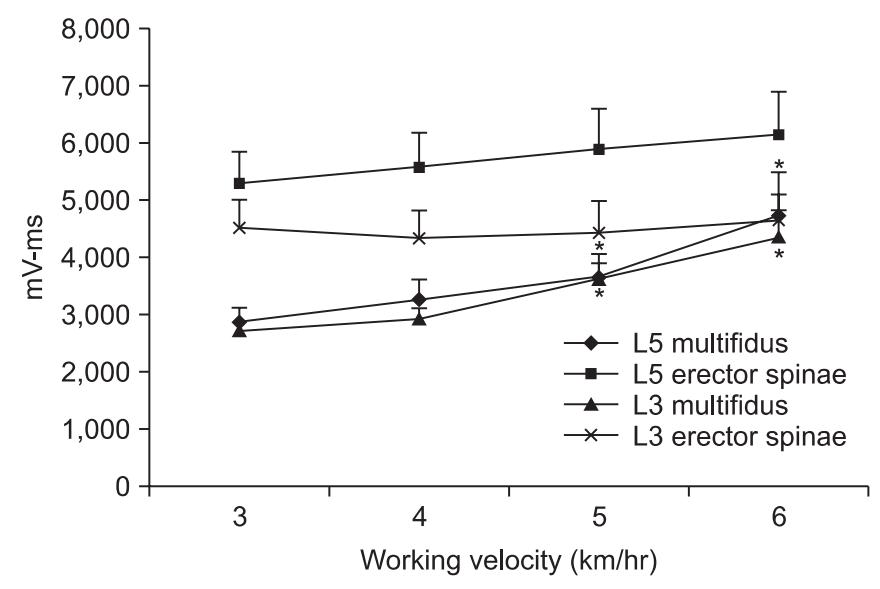

Fig. 2. Quantitative data of paraspinalis muscles activation during walking exercise at different walking speeds. ${ }^{*} \mathrm{p}<0.05$.

Table 1. Quantitative analysis of multifidus muscle activation during walking exercises

\begin{tabular}{cccc}
\hline Muscle & Velocity of walking $\mathbf{( k m} / \mathbf{h r})$ & Area under curve $\mathbf{~} \mathbf{m V} \cdot \mathbf{m s})$ & p-value \\
\hline Multifidus & & & - \\
\hline L5 & 3 & $2,869.6 \pm 811.5$ & 0.082 \\
& 4 & $3,262.0 \pm 1,127.8$ & $0.018^{*}$ \\
\hline & 5 & $3,669.6 \pm 1,240.9^{*}$ & $0.012^{*}$ \\
\hline L3 & 6 & $4,745.4 \pm 2,343.8^{*}$ & - \\
\hline & 3 & $2,712.0 \pm 517.7$ & 0.194 \\
\hline & 4 & $2,917.7 \pm 622.6$ & $0.006^{*}$ \\
\hline
\end{tabular}

Values are presented as mean \pm standard deviation.

${ }^{*} \mathrm{p}<0.05$. 
Hee Song Lee, et al.

Table 2. Quantitative analysis of erector spinae muscle activation level during walking exercises

\begin{tabular}{|c|c|c|c|}
\hline Muscle & Velocity of walking (km/hr) & Area under curve (mV·ms) & p-value \\
\hline \multicolumn{4}{|c|}{ Erector spinae } \\
\hline \multirow[t]{4}{*}{ L5 } & 3 & $5,297.6 \pm 1,747.2$ & - \\
\hline & 4 & $5,571.4 \pm 1,933.9$ & 0.393 \\
\hline & 5 & $5,888.2 \pm 2,241.8$ & 0.111 \\
\hline & 6 & $6,132.3 \pm 2,441.0$ & 0.252 \\
\hline \multirow[t]{4}{*}{ L3 } & 3 & $4,513.0 \pm 1,590.7$ & - \\
\hline & 4 & $4,336.2 \pm 1,543.0$ & 1.000 \\
\hline & 5 & $4,431.3 \pm 1,750.6$ & 1.000 \\
\hline & 6 & $4,645.8 \pm 1,459.8$ & 1.000 \\
\hline
\end{tabular}

Values are presented as mean \pm standard deviation.

Table 3. Quantitative analysis of muscle activation at L5 and L3 levels during gait at different inclinations

\begin{tabular}{|c|c|c|c|}
\hline Muscle & Gradient (4 km/hr) & Area under curve $(\mathrm{mV} \cdot \mathrm{ms})$ & p-value \\
\hline \multirow[t]{3}{*}{ L5 level multifidus } & $0^{\circ}$ & $3,262.0 \pm 1,127.8$ & - \\
\hline & $7^{\circ}$ & $3,074.8 \pm 640.1$ & 1.000 \\
\hline & $15^{\circ}$ & $3,560.7 \pm 966.6$ & 1.000 \\
\hline \multirow[t]{3}{*}{ L5 level erector spinae } & $0^{\circ}$ & $5,571.4 \pm 1,933.9$ & - \\
\hline & $7^{\circ}$ & $5,066.4 \pm 1,132.2$ & 1.000 \\
\hline & $15^{\circ}$ & $5,446.5 \pm 1,213.2$ & 1.000 \\
\hline \multirow[t]{3}{*}{ L3 level multifidus } & $0^{\circ}$ & $2,917.7 \pm 622.6$ & - \\
\hline & $7^{\circ}$ & $3,178.3 \pm 462.7$ & 0.262 \\
\hline & $15^{\circ}$ & $3,816.8 \pm 679.9$ & $0.012^{*}$ \\
\hline \multirow[t]{3}{*}{ L3 level erector spinae } & $0^{\circ}$ & $4,336.2 \pm 1,543.0$ & - \\
\hline & $7^{\circ}$ & $4,881.5 \pm 1,783.0$ & 0.074 \\
\hline & $15^{\circ}$ & $5,079.1 \pm 1,715.4$ & $0.027^{*}$ \\
\hline
\end{tabular}

Values are presented as mean \pm standard deviation.

${ }^{*} \mathrm{p}<0.05$.

muscle activation was not significantly different between the L5 and L3 levels ( $p>0.05$ ) (Fig. 2).

At the L5 and L3 levels of the erector spinae muscle, the amount of muscle activation did not increase with the change in walking speed ( $p>0.05$ ) (Table 2). The increase in erector spinae muscle activation was significantly greater at the L5 level than that of the L3 level $(\mathrm{p}<0.05)$ (Fig. 2).

\section{The effect of inclination}

At the L3 level of the multifidus, muscle activation significantly increased from $2,917.7 \pm 622.6 \mathrm{mV} \cdot \mathrm{ms}$ at a $0^{\circ}$ inclination to $3,816.8 \pm 679.9 \mathrm{mV} \cdot \mathrm{ms}$ at a $15^{\circ}$ inclination $(\mathrm{p}<0.05)$, but there was no significant increase between a $0^{\circ}$ and $7^{\circ}$ inclination (Table 3, Fig. 3). At the

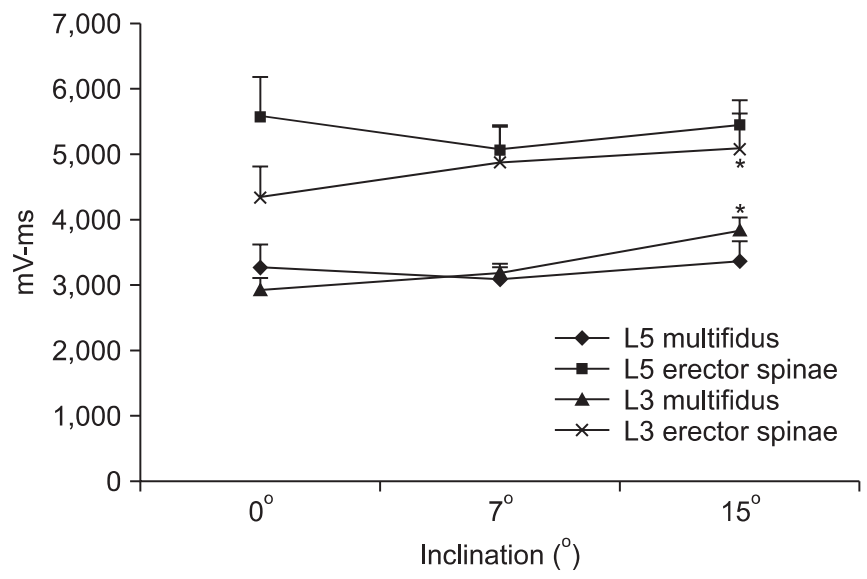

Fig. 3. Quantitative data of paraspinalis muscles activation during walking exercise at different inclinations. ${ }^{*} \mathrm{p}<0.05$ 
L3 level of the erector spinae, muscle activation also significantly increased from $4,336.2 \pm 1,543.0 \mathrm{mV} \cdot \mathrm{ms}$ at $0^{\circ}$ to $5,079.1 \pm 1,715.4 \mathrm{mV} \cdot \mathrm{ms}$ at $15^{\circ}$ inclination $(\mathrm{p}<0.05)$ between $0^{\circ}$ and $15^{\circ}$ inclination. However, there was no significant increase between a $0^{\circ}$ and $7^{\circ}$ inclination (Table 3, Fig. 3). At the L5 level, multifidus and erector spinae muscle activation at a $0^{\circ}$ inclination was not significantly different from that at a $7^{\circ}$ or $15^{\circ}$ inclination (Table 3, Fig. $3)$.

\section{DISCUSSION}

In the current study, SEMG was used to measure the amount of paraspinalis muscle activation (multifidus and erector spinae muscles) in healthy participants performing walking exercises at different velocities and inclinations. Walking exercise is widely accepted as a good choice for general back exercise and rehabilitation programs, as it strengthens the back muscles and reduces rigidity of motion [13]. Gait analysis of chronic LBP patients has shown that patients have a slower walking speed compared with healthy controls, and the coordination between transverse thoracic and pelvic rotations and lumbar and pelvic rotations was more rigid and less variable [17]. However, the effect of walking exercise on back muscles is not fully understood.

In the present study, walking exercise is shown to activate the mid or low lumbar paraspinalis muscles. In addition, high-speed walking exercise activates the multifidus muscle more than low-speed walking. The lumbar multifidus muscle plays an important role in maintaining lumbar segmental stability because it attaches and connects each segment of the lumbar spine. In previous studies that use lumbar magnetic resonance imaging, fat infiltration and unilateral atrophy of the multifidus at the symptomatic side and level were observed. In addition, the percentage of multifidus atrophy was positively correlated with the duration of symptoms. These were most prominent at the L5 vertebral level [21-23]. In another study, patients with chronic LBP had a significantly smaller percent thickness contraction at the L5 vertebral level; this reduction was not present at other vertebral levels [24]. These observations show that the size and function of the multifidus muscle are important, especially at the L5 level. Our results showed that walking exercise activates the lumbar multifidus muscle. The activation was more prominent at the L5 level than the L3 level, although there was no significant difference in activation between the L5 and L3 levels. Therefore, we suppose that walking exercise, especially fast walking, is helpful for strengthening the lumbar multifidus muscle.

In a study on the stabilizing effect of the multifidus, intraoperative sarcomere length measurements revealed that the muscle operates from $1.98 \pm 0.15 \mu \mathrm{m}$ in extension to $2.70 \pm 0.11 \mu \mathrm{m}$ in flexion. Therefore, its structure (a large cross-sectional area and low fiber length-to-muscle length ratio) demonstrates that the multifidus muscle is uniquely designed as a stabilizer to produce large forces. Furthermore, multifidus sarcomeres are positioned on the ascending portion of the length-tension curve, allowing the muscle to become stronger as the spine assumes a forward-leaning posture [25]. In walking, a forward-leaning posture is stable and comfortable, and this posture is especially exaggerated at a fast walking speed. Therefore, walking exercise, especially fast walking exercise, may be the most effective method for strengthening the multifidus muscle.

In a previous study, patients with a small cross-sectional area of the erector spinae muscle at the L5 level progressed to chronic LBP [4], indicating that the erector spinae muscle is also important. In contrast to the multifidus muscle, activation of the erector spinae muscle did not increase with walking speed. It is important to note, however, that the erector spinae muscle was still activated during walking exercise. Although not significant, muscle activation at the L5 level slightly increased with increased walking speed. Hence, we can postulate that walking exercise strengthens not only the lumbar multifidus muscle but also the erector spinae muscle, and activation of the erector spinae muscle is not dependent on walking speed.

In the present study, multifidus and erector spinae muscles at the L5 level were activated to the same extent with increasing walking slopes. However, paraspinalis at the L3 level were more activated as the walking slope increases. These findings suggest that walking at an inclination is not helpful for facilitating the low lumbar paraspinalis but is helpful for facilitating of the mid lumbar paraspinalis. Previous studies reported that paraspinalis at L5 are more correlated with back pain than those at L3. The atrophy of multifidus muscle is most prominent at the L5 vertebral level in patients with chronic LPB [4]. 
Therefore it would be reasonable to assume that walking at an inclination is not helpful to the patient with LPB, because walking at an inclination does not facilitate the low lumbar paraspinalis sufficiently.

Although our study did not evaluate the activation of muscles other than the paraspinalis muscles, other muscles, such as the quadriceps, hamstrings, and gluteal muscles, are activated differently when walking at an inclination. We should, therefore, consider other factors in walking exercise performed at an inclination, such as the facilitation of the quadriceps, cardiopulmonary function and arthritis.

Physical therapists tend to take different approaches when rehabilitating the muscles of the lower back because there is no evidence in the literature that one exercise program is superior to another. Spinal stabilization exercises are frequently used for LBP and the efficacy of these exercises have been shown in a small number of studies $[3,8,9,26]$. However, these approaches are not interesting for patients, and they may easily give up doing the exercises. Walking exercise is easily applied to physical therapy because of its accessibility and appeal. It is good for the lumbar multifidus and cardiopulmonary fitness as well.

There have been several studies using EMG to assess patients with LBP. EMG signals can be used for diagnosis and the planning of therapy by elective, quantitative measurement of paraspinal activation $[12,16,19]$. However, most of the previous studies using EMG employed maximal voluntary contraction $[12,27]$ which does not show the effect of exercise, especially isotonic exercise. Walking exercise has a low-to-moderate degree of intensity and the muscles are contracting continuously. Therefore, the amount of contraction is more important than the maximal voluntary contraction. We used the area under curve to measure muscle contraction for $20 \mathrm{sec}-$ onds. This method is more physiologically relevant and is suited to the nature of walking exercise.

This study has several limiting factors. Unfortunately, recordings made with surface electrodes over the multifidus correlate better with the activity of the lumbar longissimus than that of the multifidus [28]. Therefore, it is difficult to interpret the results of studies of the multifidus in which surface electrodes were used [29]. However, in the present study, the activation of the erector spinae muscle did not increase at higher walking velocities.
Therefore, increased EMG activity with higher walking velocities seems to reflect the activation of the multifidus muscle. A second limitation is that only male participants were included; thus, further investigation is necessary to compare male and female subjects. A third limitation is that measure the activity of paraspinal muscles in people with LBP was not measured. The activating patterns of paraspinal muscles in patients with LPB might be different from those in healthy subjects. Additional studies including patients with back pain are required.

In conclusion, we found that the fast walking exercise activates lumbar multifidus muscles more than the slow walking. In addition, the mid lumbar muscles are more activated as the walking slope increases. These results provide a clue for an optimal walking exercise protocol to strengthen lumbar paraspinal muscles in patients with LBP.

\section{CONFLICT OF INTEREST}

No potential conflict of interest relevant to this article was reported.

\section{ACKNOWLEDGMENTS}

This study was supported by a Chyung Ki Lee research grant of Korean Academy of Rehabilitation Medicine for 2012.

\section{REFERENCES}

1. Waddell G. 1987 Volvo award in clinical sciences: a new clinical model for the treatment of low-back pain. Spine (Phila Pa 1976) 1987;12:632-44.

2. Andersson GB. Epidemiological features of chronic low-back pain. Lancet 1999;354:581-5.

3. Hides JA, Jull GA, Richardson CA. Long-term effects of specific stabilizing exercises for first-episode low back pain. Spine (Phila Pa 1976) 2001;26:E243-8.

4. Lee HI, Song J, Lee HS, Kang JY, Kim M, Ryu JS. Association between cross-sectional areas of lumbar muscles on magnetic resonance imaging and chronicity of low back pain. Ann Rehabil Med 2011;35:852-9.

5. Hides JA, Richardson CA, Jull GA. Magnetic resonance imaging and ultrasonography of the lumbar multifidus muscle: comparison of two different modalities. 
Spine (Phila Pa 1976) 1995;20:54-8.

6. Hides JA, Stokes MJ, Saide M, Jull GA, Cooper DH. Evidence of lumbar multifidus muscle wasting ipsilateral to symptoms in patients with acute/subacute low back pain. Spine (Phila Pa 1976) 1994;19:165-72.

7. Stokes MJ, Cooper RG, Morris G, Jayson MI. Selective changes in multifidus dimensions in patients with chronic low back pain. Eur Spine J 1992;1:38-42.

8. Comerford MJ, Mottram SL. Movement and stability dysfunction: contemporary developments. Man Ther 2001;6:15-26.

9. Hides JA, Richardson CA, Jull GA. Multifidus muscle recovery is not automatic after resolution of acute, first-episode low back pain. Spine (Phila Pa 1976) 1996;21:2763-9.

10. Foster NE, Thompson KA, Baxter GD, Allen JM. Management of nonspecific low back pain by physiotherapists in Britain and Ireland: a descriptive questionnaire of current clinical practice. Spine (Phila Pa 1976) 1999;24:1332-42.

11. Stevens VK, Vleeming A, Bouche KG, Mahieu NN, Vanderstraeten GG, Danneels LA. Electromyographic activity of trunk and hip muscles during stabilization exercises in four-point kneeling in healthy volunteers. Eur Spine J 2007;16:711-8.

12. Ekstrom RA, Osborn RW, Hauer PL. Surface electromyographic analysis of the low back muscles during rehabilitation exercises. J Orthop Sports Phys Ther 2008;38:736-45.

13. Callaghan JP, Patla AE, McGill SM. Low back three-dimensional joint forces, kinematics, and kinetics during walking. Clin Biomech (Bristol, Avon) 1999;14:20316.

14. Anders C, Wagner H, Puta C, Grassme R, Petrovitch A, Scholle HC. Trunk muscle activation patterns during walking at different speeds. J Electromyogr Kinesiol 2007;17:245-52.

15. Saunders SW, Schache A, Rath D, Hodges PW. Changes in three dimensional lumbo-pelvic kinematics and trunk muscle activity with speed and mode of locomotion. Clin Biomech (Bristol, Avon) 2005;20:784-93.

16. Lamoth CJ, Daffertshofer A, Meijer OG, Beek PJ. How do persons with chronic low back pain speed up and slow down? Trunk-pelvis coordination and lumbar erector spinae activity during gait. Gait Posture 2006; 23:230-9.
17. Lamoth CJ, Meijer OG, Daffertshofer A, Wuisman PI, Beek PJ. Effects of chronic low back pain on trunk coordination and back muscle activity during walking: changes in motor control. Eur Spine J 2006;15:23-40.

18. Danneels LA, Coorevits PL, Cools AM, Vanderstraeten GG, Cambier DC, Witvrouw EE, et al. Differences in electromyographic activity in the multifidus muscle and the iliocostalis lumborum between healthy subjects and patients with sub-acute and chronic low back pain. Eur Spine J 2002;11:13-9.

19. Arokoski JP, Valta T, Airaksinen O, Kankaanpaa M. Back and abdominal muscle function during stabilization exercises. Arch Phys Med Rehabil 2001;82:108998.

20. Boudreau S, Farina D, Kongstad L, Buus D, Redder J, Sverrisdottir E, et al. The relative timing of trunk muscle activation is retained in response to unanticipated postural-perturbations during acute low back pain. Exp Brain Res 2011;210:259-67.

21. Barker KL, Shamley DR, Jackson D. Changes in the cross-sectional area of multifidus and psoas in patients with unilateral back pain: the relationship to pain and disability. Spine (Phila Pa 1976) 2004;29: E515-9.

22. Hides J, Gilmore C, Stanton W, Bohlscheid E. Multifidus size and symmetry among chronic LBP and healthy asymptomatic subjects. Man Ther 2008;13:439.

23. Kjaer P, Bendix T, Sorensen JS, Korsholm L, LeboeufYde C. Are MRI-defined fat infiltrations in the multifidus muscles associated with low back pain? BMC Med 2007;5:2.

24. Wallwork TL, Stanton WR, Freke M, Hides JA. The effect of chronic low back pain on size and contraction of the lumbar multifidus muscle. Man Ther 2009;14: 496-500.

25. Ward SR, Kim CW, Eng CM, Gottschalk LJ 4th, Tomiya A, Garfin SR, et al. Architectural analysis and intraoperative measurements demonstrate the unique design of the multifidus muscle for lumbar spine stability. J Bone Joint Surg Am 2009;91:176-85.

26. Danneels LA, Vanderstraeten GG, Cambier DC, Witvrouw EE, Bourgois J, Dankaerts W, et al. Effects of three different training modalities on the cross sectional area of the lumbar multifidus muscle in patients with chronic low back pain. Br J Sports Med 
Hee Song Lee, et al.

2001;35:186-91.

27. Barton CJ, Coyle JA, Tinley P. The effect of heel lifts on trunk muscle activation during gait: a study of young healthy females. J Electromyogr Kinesiol 2009;19:598606.

28. Stokes IA, Henry SM, Single RM. Surface EMG elec- trodes do not accurately record from lumbar multifidus muscles. Clin Biomech (Bristol, Avon) 2003;18:913.

29. MacDonald DA, Moseley GL, Hodges PW. The lumbar multifidus: does the evidence support clinical beliefs? Man Ther 2006;11:254-63. 